appears later in the book in the form of a series of tables. Semi-micro analysis has come to stay and older teachers, unacquainted with its techniques, could rapidly master this book and give instruction with confidence.

G. Fowles

\section{Fundamentals of Chemistry}

By Prof. L. Jean Bogert. Seventh edition. Pp. xx +648. (Philadelphia and London: W. B. Saunders Company, 1953.) 22s. $6 d$.

THE "fundamentals" are not only established but are also applied to medicine and the related arts. Of the book's thirty-two chapters nineteen deal with general chemistry and seven with organic compounds. All the chapters have been revised and some entirely rewritten: Chapter 18, on radioactivity and atomic energy, is new to this edition. In simple language and with unusual clarity Prof. Bogert gives a good introductory account of the elements and their chief compounds and of fundamental physical principles. He omits all mention of industrial processes and concentrates on the chemistry concerned with the living cell. Items of the contents illustrate this emphasis : colloids in the living organs, function of proteins in the body, physiological importance of oxidation, etc. The last six chapters deal severally with : the vitamins ; digestion and the digestive enzymes ; transportation, blood and lymph ; metabolism; endocrine glands and their hormones; elimination, urine, and fæces. The versatile author excels in these chapters, for he has the rare ability of correlating his knowledge of chemistry and physiology, of selecting what is important and of expounding its significance. The book should appeal to students of medicine, hygiene and dietetics. In addition the reviewer would recommend it for the nursing school and for domestic science where this is taken at sixth-form level.

G. Fowles

\section{Estimation of Organic Compounds}

By Dr. F. Wild. Pp. viii + 239. (Cambridge: At the University Press, 1953.) 25s. net.

7 HIs little book brings within two covers a collection of the various means of determining organic compounds through the characteristic groupings present; its scope is deliberately limited to general methods, so that the more specialized fields, for example, sugars, sulphonamides and amino-acids, are not considered.

The scheme adopted can be illustrated by the treatment accorded to olefinic linkages. Hydrogenation, both on the macro- and micro-scale, is described in detail, as are also methods for bromine, iodine and thiocyanogen numbers and the allied. process using peracids; there are also a number of miscellaneous methods given in brief form. The inclusion of iodine numbers in a book of this kind is interesting, since it is usually necessary to refer to works on applied analysis of more specialized character for descriptions of such methods.

Other classes treated on similar lines are alcohols and phenols, mercaptans, aldehydes and ketones, amines, nitriles, nitro-, acetyl- and benzoyl-compounds and the lower alkyloxy- and alkylimino-compounds. A few others, for example, nitroso compounds and isocyanates, are discussed in less detail. In some of the classes, particular methods for some individual members are included, for example, methanol (but not ethanol), formaldehyde, acetone. The Karl Fischer reagent is introduced under carbonyl compounds.
Experience would soon reveal that the 60 per cent strength quoted (p. 36) for $a$ toluene solution of maleic anhydride is incorrect ; the spelling 'xylidene', which occurs more than once, is unusual. These are, however, minor blemishes on a work which, with its companion volume in the qualitative field, will give the organic chemist a sound and useful start.

B. A. Elluis

\section{A Short Course in Organic Chemistry}

By Harold Hert and Robert D. Schuetz. Pp. ix +326 . (Boston, Mass.: Houghton Mifflin Company, 1953.) 4.50 dollars.

TE format, for a book of this class, is uncommon; its dimensions in inches, $10 \frac{1}{4} \times 6 \frac{1}{5} \times 7^{7} \pi$, and its large clear type permit of the bold presentation of important notes. The illustrations are varied and striking; indeed, the line drawings, the many plates in half-tone, the pictures of electron clouds, and the numerous ball-and-peg molecular models, disclose the authors' confidence in visual aid. The course, framed for adult students who need a working knowledge of organic chemistry but whose main interest lies in such fields as those of medicine, dentistry and agriculture, follows no prescribed syllabus. The scope is roughly the requirements in organic chemistry of the British university first-year course, but includes also the simple chemistry of petroleum, plasties, rubber, textiles, dyes, and explosives, as well as of vitamins, hormones and antibiotics. The approach is not by the study of alcohol, or by the analysis of organic compounds-a section entirely omitted-but by the electronic theory and the explanation of simple reaction mechanisms. The judgment shown in the selection and arrangement of the material is to be commended. The main emphasis is on biological aspects and on everyday applications of recent discoveries. The treatment is clear and interesting, yet a topic requiring effort for its understanding, such as optical isomerism, is not avoided. In general, aliphatic and aromatic compounds are treated together. The simple applications of the electronic theory, the use made of the structure of molecules, and the up-to-date information should commend this book to teachers as well as to the class of students for whom it was written. G. FowLes

\section{Notes on Qualitative Analysis}

By H. J. H. Fenton. A new edition, by Dr. B. C. Saunders. Pp. vii +126 . (Cambridge: At the University Press, 1953.) 15s. net.

THAT many years have passed since this book was revised is a testimony to the worth of Fenton's tables of analysis and to his selection of reagents. Dr. Saunders has put into this edition not only his own experience but also that of his colleagues at Cambridge. He has changed the tables but slightly, adding here and there an alternative separation, and he has inserted a well-chosen selection of modern reagents and procedures. Among these are Holness's effective way of bringing the arsenic group sulphides into solution and both the titanium and the zirconium methods for the removal of phosphate. Apart from this, with the purpose of extending the use of the book to the sixth form of schools, he has made considerable alterations. Gone are the fifty pages on the reactions of organic compounds and in place appears a section on microanalysis. Dr. Saunders has rewritten the notes on theory, he has removed from the analytical tables substances not found in Advanced Level (General Certificate) syllabuses, and 